\title{
NOTES ON A RARE CASE OF ESSENTIAL OSTEOLYSIS
}

\author{
Francisco Branco and J. da Silva Horta, Lisbon, Portugal \\ From the Institute of Oncology, Lisbon
}

In 1944 a schoolboy, then aged thirteen, was wounded slightly in the right foot by a nail, which caused a moderate lymphangitis of the leg. A month before, while running, he had felt his right leg give way momentarily. A few days after the injury to his foot, while he was bathing in the sea and already recovered from the trauma, he suffered a sudden pain in the right groin which increased rapidly and became very severe a few hours later. There was marked pyrexia, with rigors, and examination showed a diffuse tender swelling of the right thigh and limitation of hip movements. Under sulphonamide treatment the fever and pain subsided and full hip movement was regained within a week. However, from that time, whenever the patient walked his leg would become affected with oedema of the thigh and knee, which would disappear with rest.

A few days later the same clinical picture of pyrexia preceded by rigors recurred; hip and knee movements were greatly impaired, and there was lymphadenitis in the groin. Sulphonamide treatment was resumed and the patient felt well after three days, with disappearance of the

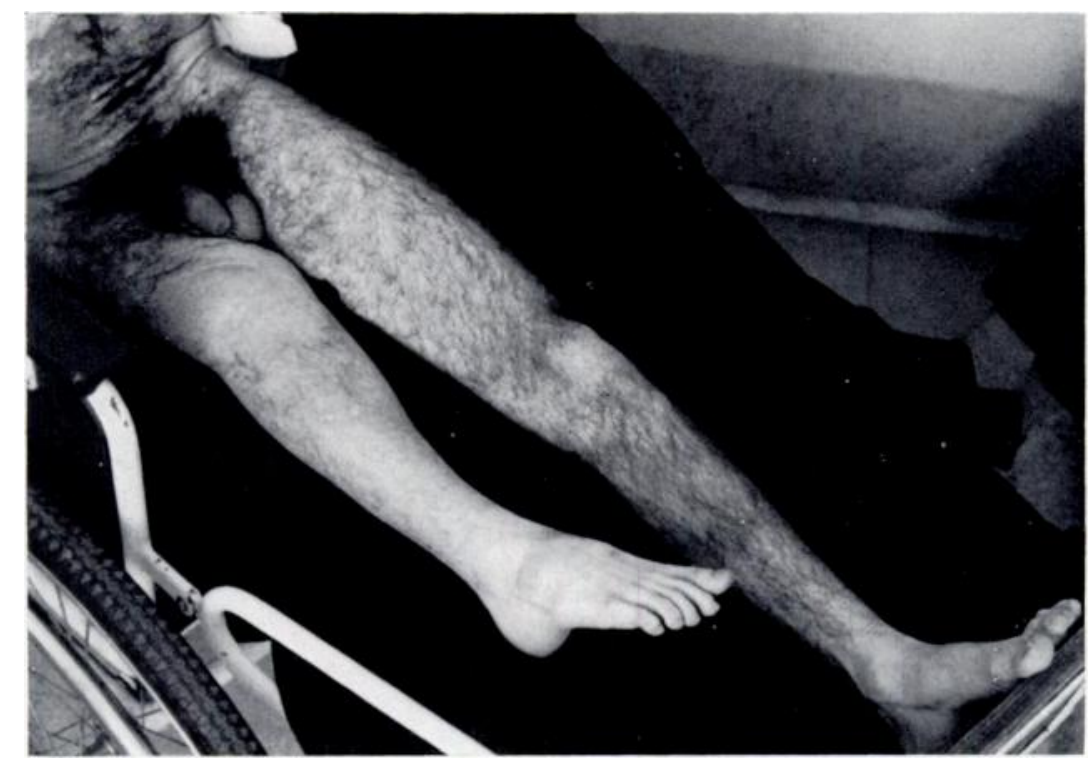

Fig. 1

Photograph showing the marked shortening of the right thigh.

fever, but rest in bed was continued for two weeks on account of the persistent inguinal lymphadenitis. Painless, mobile lymph nodes could be felt, the size of small cherries, without any cutaneous reaction.

The patient returned to his normal activities, but he continued to note a swelling of the right thigh, spreading downwards to the knee, especially at the end of the day. This oedema gradually became more persistent and severe, until it continued to exist even with rest. 


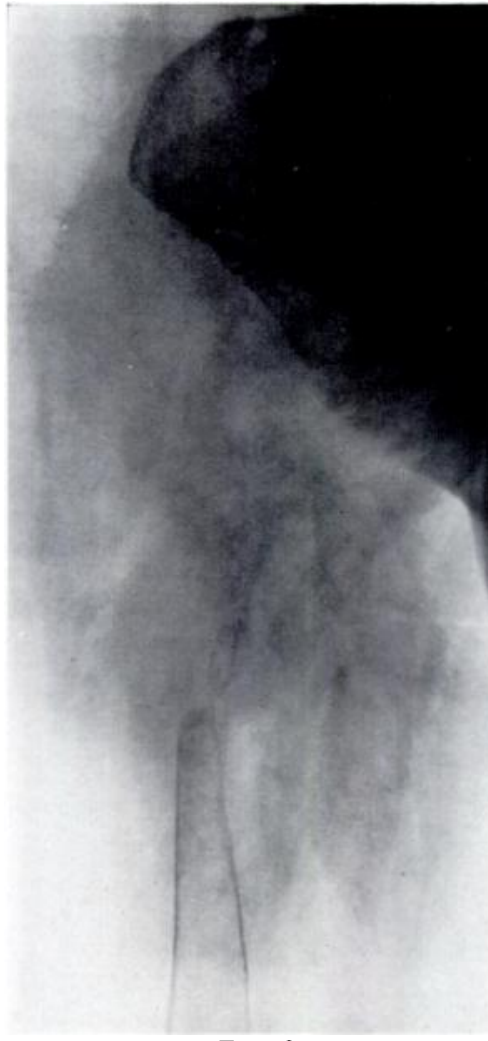

FIG. 2

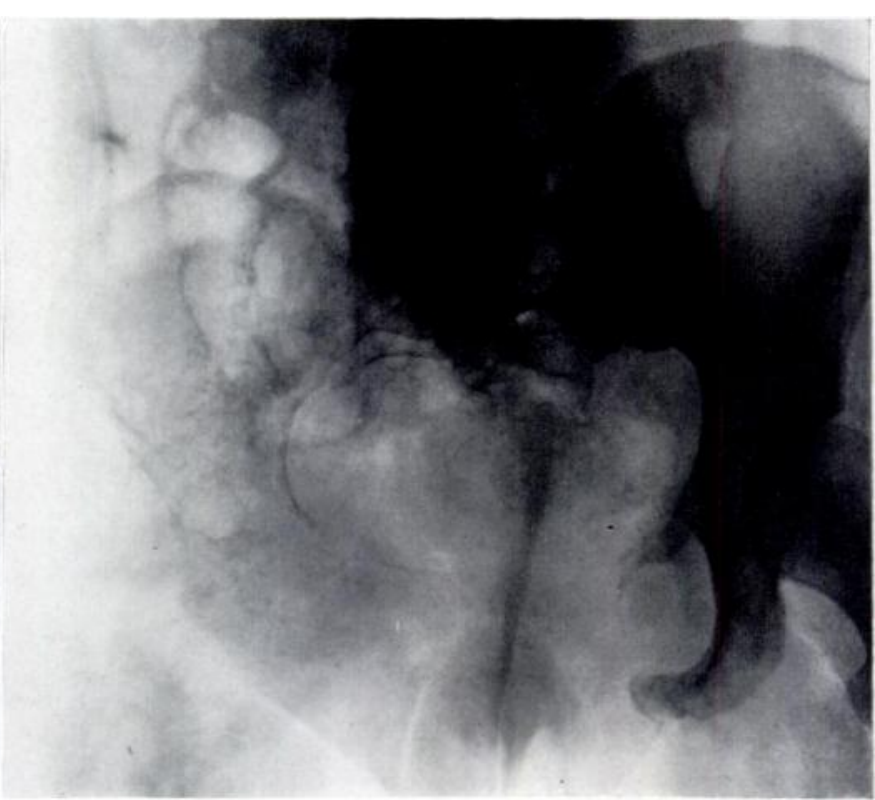

FIG. 3

Figure 2-Right thigh showing total destruction of the upper two-thirds of the femur. Figure 3-Pelvis (1950) showing disappearance of a large part of the right half of the pelvis and sacrum, with beginning destruction of the left pubis and ischium.

About four months later a yellowish discoloration appeared on the inner aspect of the thigh, changing to a purplish tone before disappearing some time later. The area was hard but painless. Although the thigh and knee remained swollen, the patient could walk without

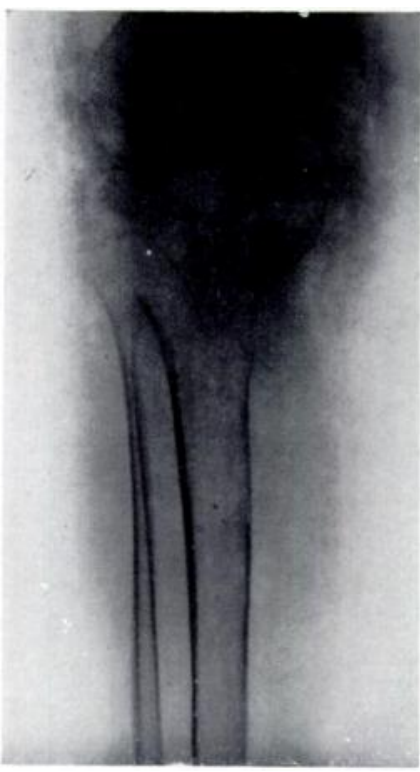

Fig. 4

Right knee and upper parts of tibia and fibula in 1950. Partial atrophy of fibula. limping, could run well and had no pyrexia. Radiographs did not reveal any local abnormality.

Despite massage, anti-streptococcal vaccines and lumbar sympathetic infiltrations of procaine, the clinical picture continued to progress, with gradually increasing swelling. Function was but little impaired until August 1945-eleven months after the onset-when a spontaneous fracture occurred at the junction of the middle and uppermost thirds of the right femur. Radiographs showed marked rarefaction of the femur and a complete oblique fracture. A tentative diagnosis of Ewing's sarcoma was made. A plaster was applied and radiotherapy given in two courses with an eight months' interval. The patient's general health remained good, but radiographs showed progressive rarefaction of the femur. The lymph nodes in the groin could no longer be felt.

In April 1947, twenty months after the fracture, hormone treatment with hexoestrol was begun and maintained for about a year. This caused a marked gain in weight, with considerable gynaecomastia.

Successive radiographic examinations revealed a spreading of the bone destruction downwards to involve the knee joint, and upwards to involve the pelvis, including the sacrum. 


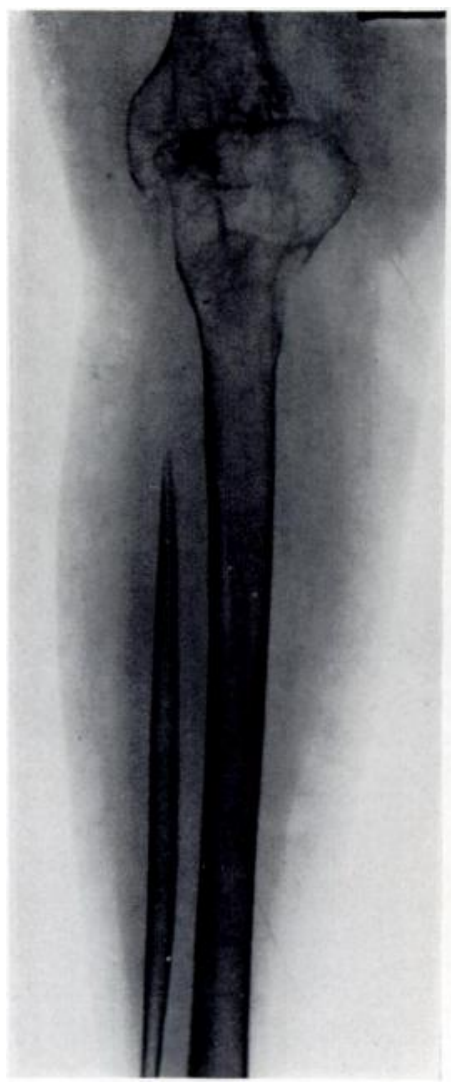

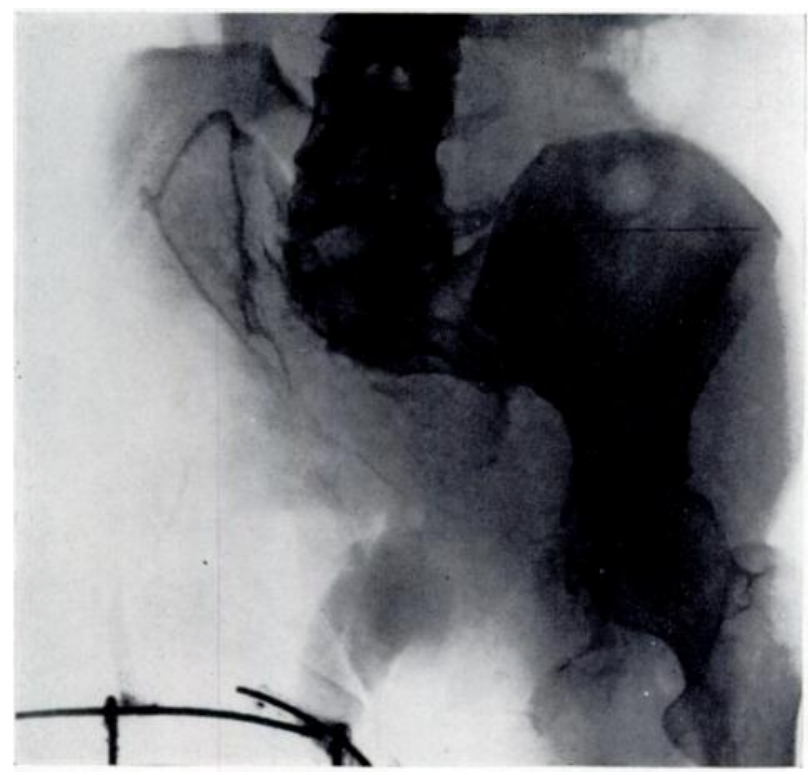

FIG. 6

Figure 5-Right knee and upper parts of tibia and fibula in 1956 showing increased destruction of fibula. Figure 6-Pelvis in 1956 showing further destruction of the right ilium and left pubis and ischium.

At this time the plaster had to be discarded because of intolerance of the skin. The limb was very much shortened, and presented grossly abnormal mobility.

In January 1950, about six years after the onset of the illness, the patient first came under our care. He was then nineteen years old and very fat. He moved about in a wheel-chair, resting on what remained of his pelvis, with his right leg in a splint. Examination revealed nothing except the abnormality of the right lower limb, which, deprived of all voluntary movement, was greatly deformed and about twenty centimetres shorter than the left (Fig. 1). The skin, covered with hair and without any trophic changes, was wrinkled with transverse folds, and was strangely mobile over the deep layers. The muscles were flaccid. The right foot, though smaller than the left, was not deformed and could be flexed and extended. The whole limb was painless to the touch and to pressure, and the consistency of the tibia and patella was normal, although the latter was deformed. The knee was totally ankylosed. The limb was strikingly flexible and could be bent painlessly in all directions, the movements being limited only by the soft parts.

Radiographic examination-Radiographs (1950) showed that the upper two-thirds of the right femur, together with the lower half of the right innominate bone and part of the sacrum, had completely disappeared (Figs. 2 and 3). The destructive process had extended across the symphysis pubis to the left half of the pelvis. The right ilium, the lowest third of the right femur, and the right tibia and fibula were markedly rarefied (Fig. 4). A skeletal survey showed no alteration of any other bone (Fig. 7). Pyelography did not reveal any abnormality of the renal tract. Later radiographs, taken in 1956 and showing increased destruction of bone, are shown in Figures 5 and 6.

VOL. $40 \mathrm{~B}$, NO. 3, AUGUST 1958 
Investigations - Repeated laboratory tests, including serum calcium (10.4 milligrams per cent), serum phosphorus ( $3 \cdot 1$ milligrams per cent) and alkaline phosphatase ( $4 \cdot 2$ Bodansky units) estimations, blood counts, erythrocyte sedimentation rate, urine examinations, Sulkowitch's calcium excretion test, Wassermann reaction, and blood sugar and blood urea determinations,

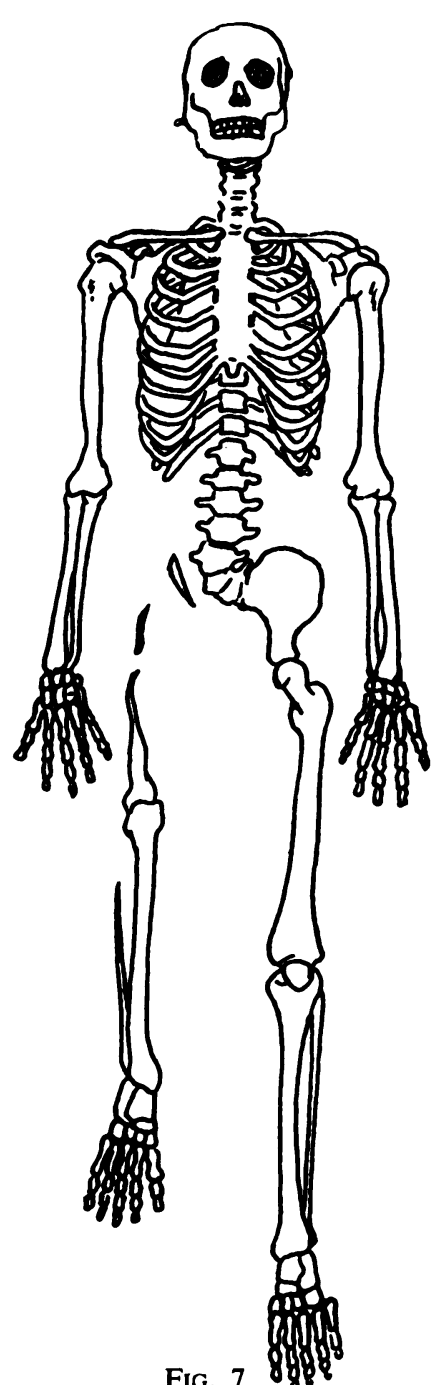

Diagram showing the distribution and extent of the bone destruction in 1956. were all normal. The basal metabolic rate was plus 21 per cent. The electrophoretic curve, for a total value of 6.28 grains of protein, was within normal limits. Test meal was normal, as was the cerebrospinal fluid. Calcium balance studies showed that there was no abnormal loss of calcium from the body. The only finding that was constantly abnormal was the blood magnesium concentration, which was low at $1 \cdot 1$ milligrams per cent.

Biopsy-During the past six years we have made three biopsies, the first specimen being removed from the crest of the right ilium, and the last two from the lowest third of the femur.

The most recent biopsy, in March 1957, included fragments of the femur, of muscle and of nerve tissue. The exposed region appeared normally vascularised and the remains of the right femur (little more than the lowest third) were approached through poorly developed muscular masses. The appearance and consistency of the bone were normal and the upper extremity of the bone terminated sharply, like a pencil point.

Histological studies (Professor J. da Silva Horta)(Figs. 8 to 11)The remaining bone contained Haversian canals that were widened and filled with fatty marrow. The lamellae were for the most part regularly arranged, but there were cement lines that were sometimes numerous and oriented in different directions, resulting in irregular mosaic figures. At the edge of the bone, adjacent to the fibrous type of tissue to be mentioned later, there was newly formed lamellar bone, but the lamellae were disposed at right angles to those of the old bone substance. This feature was seen in all the sections, regardless of the method of preparation, but was seen especially clearly in silver impregnations (Tibor-Pap). In the new bone osteocytes were numerous. There was also osteoid substance at the edge of the bone, but only in small quantity. The bone substance presented an intense rearrangement in which the process of destruction exceeded that of repair. In addition to the widening of the Haversian canals, the initially compact bone was transformed into spongy bone; the intervention of osteoclasts was practically

nil. The essential process was a replacement of bone substance by an unusual connective tissue. This was a basophilic substance containing connective fibres with an undulated, winding trajectory. Some of these fibres were thick and slightly eosinophilic, staining blue and yellowish grey by Van Gieson's stain. Many of these fine and coarse fibres were impregnated by silver, and there were elastic fibres among them.

Isolated masses of this peculiar fibrous tissue appeared in the midst of ordinary loose connective tissue, just as if they represented already demineralised trabeculae of bone, but with a perfectly preserved contour which permitted their individualisation. The limits of one of these masses were marked by curved fibres, just as in a capsule. These masses of special tissue contained a few scattered capillaries and a few cells, many with pyknotic nuclei. There 


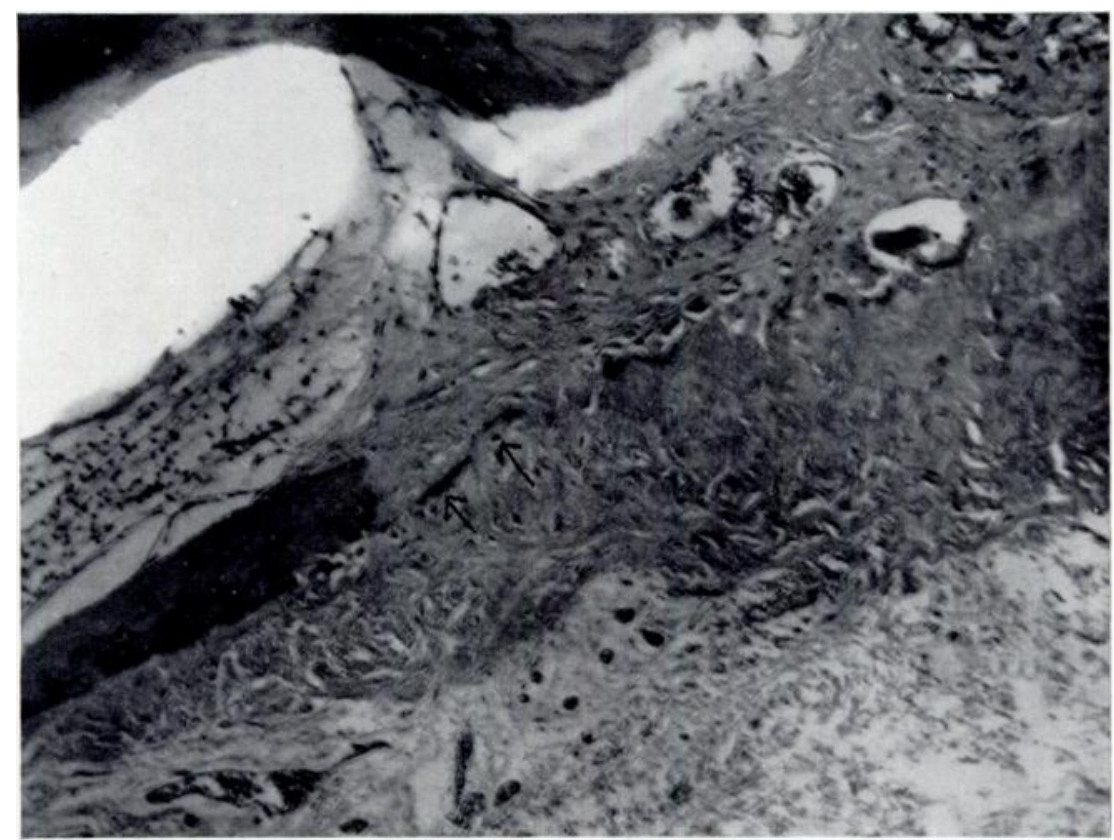

FIG. 8

Low power photomicrograph of a section from the right thigh showing an intense osteolytic process. The bone trabeculae are transformed into a matrix of unusual appearance, in the midst of which may be seen the remains of mineralised trabeculae (arrows). (Haematoxylin and eosin.)

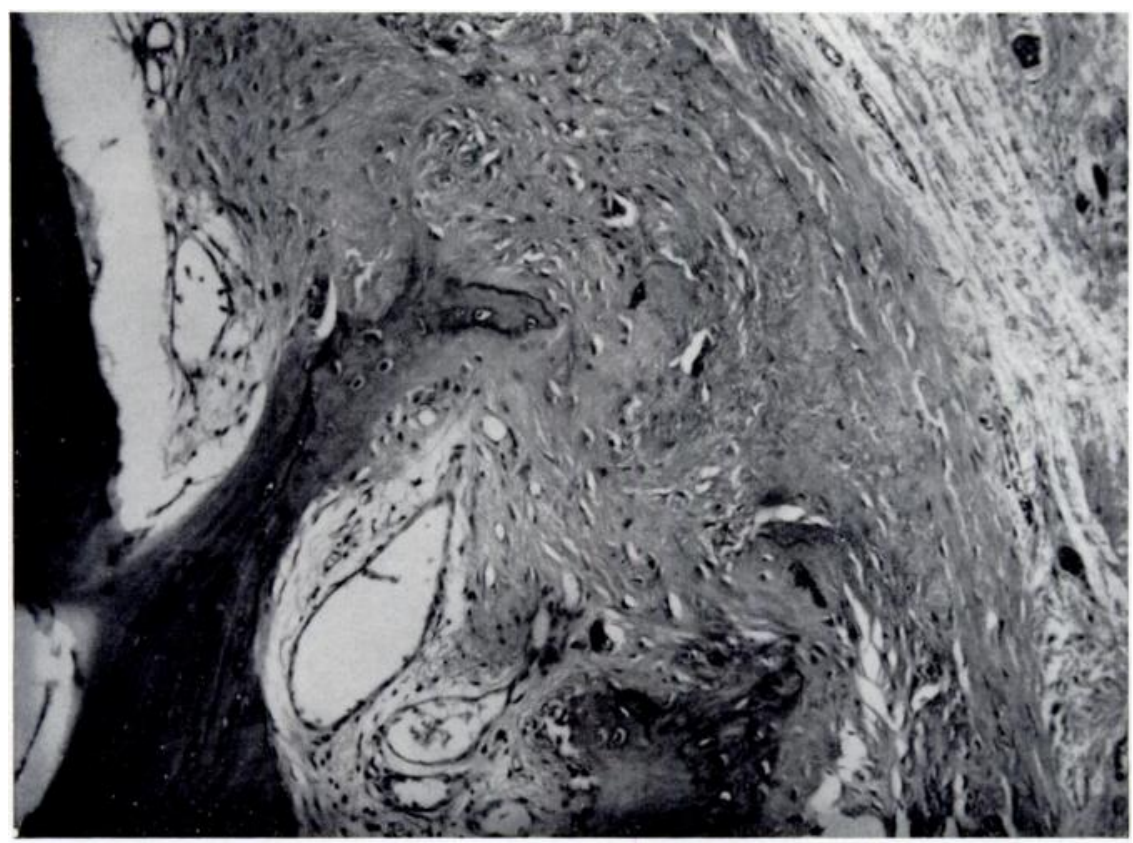

FIG. 9

Another part of the material, showing the same osteolytic process. The same special matrix is seen, already decalcified, with bony trabeculae in the course of transformation. (Haematoxylin and eosin.) 


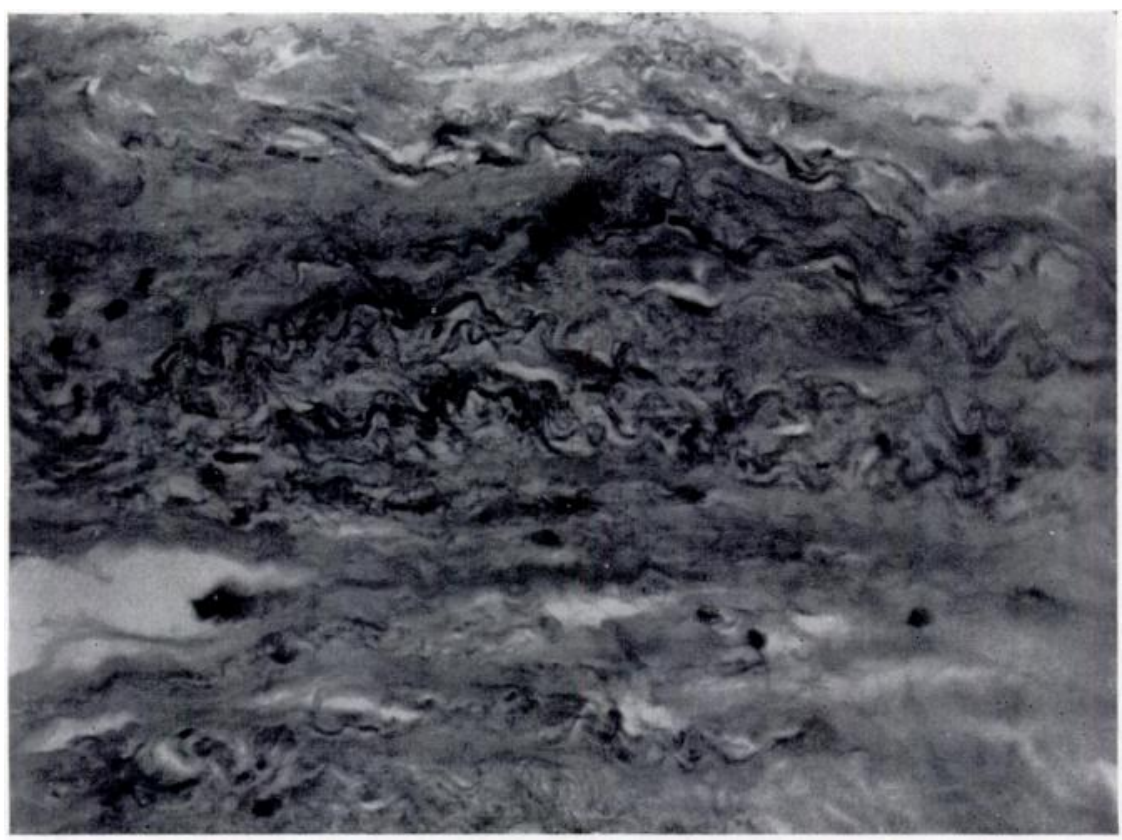

Fig. 10

The matrix referred to in the preceding figures contains undulated fasciculi. (Haematoxylin and eosin; medium magnification.)

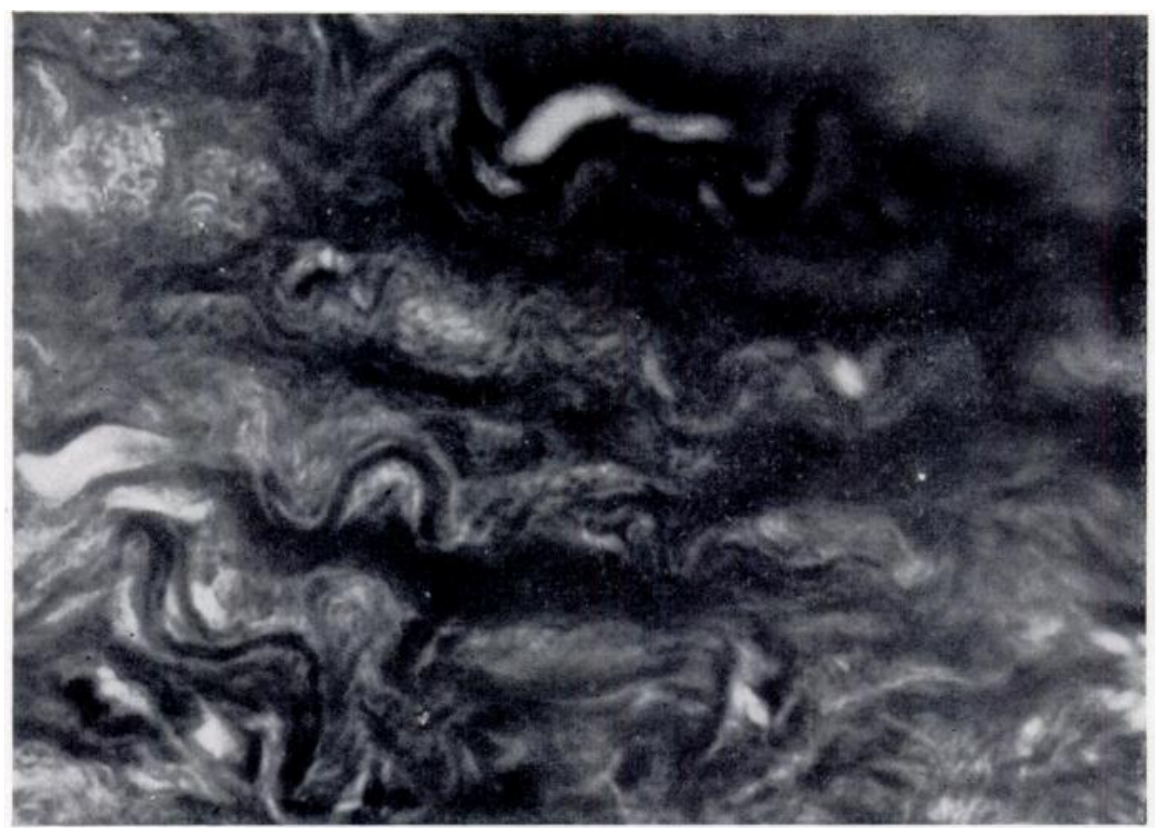

FIG. 11

The same undulated and tangled fasciculi as those seen in Figure 10. (Mallory stain; high magnification.) 
were interstitial spaces in this tissue which communicated with large empty areas. Sometimes small fragments of the tissue described were scattered throughout a loose oedematous connective tissue. In other places the bone was continued either by dense fibrous connective tissue, with a variable number of histiocytes and fibroblasts, or by slightly irregular cartilaginous tissue, or by a special tissue that was in general fibrous, but which contained one or another element of the type of cartilaginous cells. With the Mallory or Tiber-Pap stains it was verified that at certain points the fibres of the bone substance were continued by those of the dense or cartilaginous fibrous tissue, and also by those of the fibrous basophile tissue. There was no evidence of active osteoclasis; one or two osteoclasts might be found in the fibrous eosinophil tissue and in a very restricted zone close to small remains of bony trabeculae that persisted in the fibrous mass. There was active bone marrow in several places.

The striped muscle presented important alterations: some fibres showed a variable degree of atrophy, others showed loss of striation, and still others were transformed into intensely eosinophil hyaline masses. There was slight proliferation of the nuclei of the sarcolemma, and infiltration around the vessels by small round lymphoid cells. There was some proliferation ex-vacuo of the adipose and fibrous tissues. The latter possessed slightly undulated fibres, but they were basophilic.

In the loose connective tissue surrounding the muscle, and separating it from blood vessels, there were several lymphocytic infiltrations. In this same tissue there were irregular spaces filled with fibrinous detritus which was either free or disposed in fasciculi along the edges of the spaces.

The nerves were deeply infiltrated by a basophilic metachromatic (toluidine blue) substance. The axons were intensely altered, with disappearance of various segments, pronounced swellings, sometimes the beginning of rosary formation-that is, with widened portions alternating with very fine ones. In addition to this, there were several isolated segments of the axons which were curved in an arc. The myelin sheaths were relatively intact.

TABLE I

Comparative Analyses of Fluid from the Patient's THIGH AND Blood SERUM

\begin{tabular}{|c|c|c|}
\hline \multirow{2}{*}{ Constituent } & \multicolumn{2}{|c|}{$\begin{array}{c}\text { Content } \\
\text { (milligrams per cent) }\end{array}$} \\
\hline & Aspirated fluid & Blood serum \\
\hline Calcium . & $8 \cdot 7$ & $10 \cdot 1$ \\
\hline Phosphorus & $3 \cdot 1$ & $2 \cdot 7$ \\
\hline Alkaline phosphatase & $3 \cdot 1$ & $2 \cdot 0$ \\
\hline
\end{tabular}

Further treatment and progress-On three separate occasions we withdrew, from the depths of the thigh and of the sacral region, sero-sanguineous fluid in abundance. The study of this fluid showed that most of the cellular elements were red blood cells, with lymphocytes and polymorphonuclear cells also present, with isolated macrophages and cells of the histiocyte type. The electrophoretic curves of proteins obtained from blood serum and from this fluid were identical. Chemical analysis of the fluid supported the probability that the fluid was derived from the blood (Table I).

\section{DISCUSSION}

With no precise knowledge of the etiology or pathogenesis of the condition, the anatomical and histological observations can help us but little to explain its nature.

vol. $40 \mathrm{~B}$, No. 3, AUGUST 1958 
In the presence of such results, some investigators have suggested an active hyperaemia conditioning the reabsorption of the bone and its substitution by fibrous tissue. We meet expressions such as: "fibrous tissue rich in blood vessels," " marrow replaced by fibrous tissue rich in vessels," "appearance of fibrocystic disease," in the reports of the rare cases that have been examined from the histological point of view.

In the opinion of Gorham and Stout (1955) the active vascularisation would be responsible for the disturbance of the osteoblast-osteoclast balance, with predominance of the destructive activity in relation to the laying down of bone, resulting in bone resorption. In our case the part played by osteoclasts was practically nil, as judged from the three pathological specimens. In some cases the disease seems to be associated with a haemangioma. Leriche (1937) suggested that the process might take place in the presence of hyperaemia caused by injury or infection, and that the increase in local arterial circulation might be the cause of the osteolysis. But, we ask, might not the hyperaemia, if present, be the consequence of the process, a secondary phenomenon? In the three biopsies made in our case, we did not observe any sign of local increase in vascularity.

Mouchet (1943) affirmed that injury, which has been a feature in some cases, is always slight, has no effect on the genesis of the condition and has no greater significance than that of revealing a disease already in evolution.

Leger, Ducroquet and Leger (1949), Coste and Gaucher (1943) and others have suggested that the condition might be of neurogenic origin, associated with or depending upon a lesion of the central nervous system, of the medullary autonomic centres or of the hypothalamic centres.

In our case it seemed as if the stroma, the osteoid tissue, had lost the capacity to fix electrolytes and had liquefied its muco-protein structure by an enzymatic process.

In most of the twenty-five cases of this obscure disease that have been reported the patients have been children or young adults. The sites at which the disease has started include the clavicle, sternum, ribs, humerus, radius, ulna, small bones of the wrist, metacarpal bones, fingers, maxilla and mandible, bones of the foot, femur and pelvis. In our case the lysis involves the fibula, the femur, the ilium and the sacrum on the right side, and has already destroyed a large part of the ischium and the pubis on the left. The upper part of the right tibia and the lower lumbar vertebrae are already seriously rarefied.

The evolution of the disease is, as in our case, lengthy, painless, afebrile and often complicated by fractures.

The breakdown of the bone resists all the therapeutic measures tried so far, and tends to progress (Figs. 5 and 6).

In this case we started with androgens, continuing their administration for a long time, up to a total of 2 grains of testosterone propionate, as a result of which the patient lost some 20 kilograms of weight. Later we added calcium fluoride, without any visible benefit. We also tried suprarenal extracts (in view of the importance of the function of these glands in the elimination of electrolytes), vitamin $\mathrm{D}_{2}$, aluminium acetate solution, ultra-violet radiation and ionised calcium, and somatotrophic hormone. The prolonged administration of placental extracts, of vitamin $B_{12}$ and of other vitamins and amino acids, was useless. We made transfusions of placental blood and a series of transfusions of blood obtained from young individuals whose growth had not yet terminated, with the idea that the blood of such individuals would be richer in bone factors than that of mature individuals. These transfusions were of no avail. Since experimental fractures have been found to heal more rapidly when the animal receives small doses of Bogomoletz serum (Straus et al. 1946) we tried this serum for a long time, but without any benefit.

We did not attempt a bone-grafting operation, fearing that the graft would only disappear, as described by Dupas, Badelon and Dayde (1939). 
SUMMARY

1. A case of essential osteolysis, progressing for thirteen years and involving the right femur and pelvis of a boy who was thirteen years old at the time of onset, is presented.

2. The histological appearance of fragments of bone and soft tissue removed from the affected thigh is described.

3. No evidence that might throw light on the etiology of the disease was obtained from biochemical investigations or from the histological studies.

4. None of the many lines of treatment that were tried had any effect upon the progress of the disease.

A clinical report on this patient was published simultaneously by Dr João José Ferro and by Dr Barros do Amaral in 1950. We consider that this further report on the same patient is justified by the rarity of the condition and by the further biochemical and histological investigations that we have carried out.

\section{REFERENCES}

Albright, F., and Reifenstein, E. C., Jun. (1948): The Parathyroid Glands and Metabolic Bone Disease. Baltimore: The Williams \& Wilkins Company.

Amaral, B. (1950): Un caso raro de ostéolise essencial " osso fantasma." Imprensa Médica, Lisboa, 14, 111. Blau, M., Spencer, H., Swernov, J., and Laszlo, D. (1954): Utilization and Intestinal Excretion of Calcium in Man. Science, 120, $1,029$.

BOGAERT, L. van (1940): Sur les arthropathies mutilantes symétriques des extrémités inférieures et leurs rapports avec la syringomyélie. Presse Médicale, 48, $1,026$.

Chiappa, S., and Pagano, G. (1955): Sur l'affection dite ostéolyse de nature essentielle. Journal de Radiologie et d'Electrologie, 36, 870.

Coste, F., and Gaucher, M. (1943): Ostéolyses d'origine nerveuse. Revue du Rhumatisme, 10, 51.

Dupas, J., BADElon, P., and DAYDE, G. (1939): A propos d'un cas d'ostéolyse essentielle progressive de la main gauche. Journal de Radiologie et d'Electrologie, 23, 212.

Ferro, J. J. (1950): Um caso (o primeiro?) de ostéolise essencial em Portugal. Clínica Contemporânea, 4, 262. Gennes, L. de (1957): Maladies des glandes parathyroïdes. In Maladies des glandes endocrines, p. 189. Paris: Flammarion.

Gorham, L. W., and Stout, A. P. (1955): Massive Osteolysis (Acute Spontaneous Absorption of Bone, Phantom Bone, Disappearing Bone). Journal of Bone and Joint Surgery, 37-A, 985.

Gorham, L. W., Wright, A. W., Shultz, H. H., and Maxon, F. C., Jun. (1954): Disappearing Bones: A Rare Form of Massive Osteolysis. Report of Two Cases, One with Autopsy Findings. American Journal of Medicine, $17,674$.

JaCobs, E., Bastenie, P. A., and Meyers, A. (1953): Arthrite mutilante avec ostéolyse progressive des membres supérieurs. Acta Clinica Belgica, 8, 447.

LANCET (1956): Unexplained Osteolysis. (Annotation.), i, 93.

Leger, L., Ducroquet, R., and Leger, H. (1949): Ostéolyse dite essentielle. In Maladies du Squelette, p. 190. Paris: Masson et Cie.

LEGER, L., LièVRE, J. A., and Mme LièVRE, J. A. (1953): Ostéose parathyroïdienne par épithélioma parathyroïdien. Presse Médicale, 61, 1,741.

LeRICHE (1937): A propos des ostéolyses d'origine indéterminée. Mémoires de l'Academie de Chirurgie, 63, 418.

Lichtwitz, A., Parlier, R., and Hioco, D. (1955): Physiopathologie et traitement des ostéomalacies. Semaine des Hôpitaux de Paris, 31, 900.

LOEPER, M., and LESOBRE, R. (1943): Un cas d'ostéolyse distale au cours d'un rhumatisme psoriasique. Revue du Rhumatisme, 10, 37.

Mouchet, A. (1943): Ostéolyses post-traumatiques. Revue du Rhumatisme, 10, 43.

Mouchet, A., and Simonin, L. (1943): Ostéolyse du cubitus et syndrome de Volkmann. Revue d'Orthopédie, 29, 22.

PiCard, J. (1955): Action de la parathormone dans le métabolisme phosphocalcique. Presse Médicale, 63, 1,320. Pizon, P. (1956): Ostéolyse post-traumatique partielle d'une apophyse articulaire lombaire génétiquement anormale. Presse Médicale, 64, 1,572.

Straus, R., Horwitz, M., Levinthal, D. H., Cohen, A. L., and Runjavac, M. (1946): Studies on Antireticular Cytotoxic Serum. Journal of Immunology, 54, 163.

vol. 40 B, No. 3, AUGUST 1958 